\title{
"Kissing" Aneurysms of the Internal Carotid Artery Treated by Coil Embolization -Case Report-
}

\author{
Chiaki TAKAHASHI, ${ }^{1}$ Michiya KUBO, ${ }^{1}$ Soushi OKAMOTO, ${ }^{1}$ \\ Nobuhisa MATSUMURA, ${ }^{1}$ Yukio HORIE, ${ }^{1}$ Nakamasa HAYASHI, ${ }^{2}$ \\ Naoya KUWAYAMA, ${ }^{2}$ and Shunro ENDO ${ }^{2}$
}

${ }^{1}$ Department of Neurosurgery, Saiseikai Toyama Hospital, Toyama, Toyama; ${ }^{2}$ Department of Neurosurgery, Faculty of Medicine, University of Toyama, Toyama, Toyama

\begin{abstract}
A 62-year-old female complaining of sudden severe headache was referred to our stroke center in consultation. Computed tomography showed diffuse spread of thick subarachnoid hemorrhage to the basal cistern and both sylvian fissures, and digital subtraction angiography showed kissing aneurysms arising in the left lateral and occipital directions in the $C_{1}$ portion of the internal carotid artery (ICA). The anterior choroidal artery was situated between the two aneurysms, and another small branch originating from the dome of the distal aneurysm was confirmed as a duplicated middle cerebral artery (MCA). Endovascular treatment was successfully performed to spare the two vessels involved. This case of kissing aneurysms and ICA-duplicated MCA is very rare, and presents difficulties for both surgical and endovascular treatments.
\end{abstract}

Key words: kissing aneurysm, coil embolization, anterior choroidal artery, duplicated middle cerebral artery, treatment strategy

\section{Introduction}

Kissing aneurysms are dual, adjacent aneurysms arising from separate points of origin, ${ }^{8)}$ with an incidence of only $0.2 \%$, based on operative findings. ${ }^{28)}$ This rare phenomenon often poses diagnostic and treatment difficulties. ${ }^{28)}$ The internal carotid artery-posterior communicating artery (ICA-PCoA) and the ICA-anterior choroidal artery (AchA) are most commonly involved, ${ }^{10,15,23)}$ although lesions of the anterior cerebral artery, ${ }^{20}$ anterior communicating artery, ${ }^{17)}$ and fenestrated basilar artery ${ }^{5,22)}$ have also been described. Aneurysm developing from a duplicated middle cerebral artery (MCA) is rare and may be equally challenging. ${ }^{12)}$ We describe an unusual case of kissing aneurysms, involving an ICA-duplicated MCA, as well as an ICAAchA, and manifesting as subarachnoid hemorrhage (SAH) after rupture.

\section{Case Report}

A 62-year-old woman was transported by ambulance to the nearest local emergency center, complaining of sudden severe headache. On arrival, she was comatose, but no lateralizing motor deficits were evident. Computed tomography (CT) showed diffuse spread of thick SAH to the

Received November 30, 2010;

Accepted February 16, 2011 basal cistern and both sylvian fissures. Her condition was grade 4 by the Hunt and Kosnik classification, and Fisher CT designation was group 3. Systolic blood pressure was maintained below $120 \mathrm{mmHg}$ with nitroglycerin/diltiazem infusion and mild sedation (diazepam and pentagin). She was then referred to our stroke center in consultation.

On admission, the patient's level of consciousness had improved considerably to E3V4M6 by the Glasgow Coma Scale, even with sedation. Three-dimensional (3D) CT angiography subsequently detected adjacent kissing aneurysms of the left ICA. Rotational 3D digital subtraction angiography showed the aneurysms arose in the left lateral and occipital directions in the $\mathrm{C}_{1}$ portion of the ICA. The proximal aneurysm measured $4.9 \mathrm{~mm} \times 3.7 \mathrm{~mm}$, and the distal aneurysm $4.0 \mathrm{~mm} \times 4.2 \mathrm{~mm}$, was slightly smaller (Fig. 1). The AchA originated near the aneurysm neck on the dome, traversed the choroidal point to supply the choroid plexus, and also passed between the two aneurysms. Another small branch split from the dome of the distal aneurysm, running parallel to the left MCA to supply the frontal tip of the temporal lobe (Fig. 2). MCA duplication was confirmed from the general orientation.

We chose endovascular treatment to spare the two vessels involved, as the AchA, situated between the two aneurysms, was unlikely to be spared using neck clipping. The larger bleb aneurysm, located proximally, was the suspected source of rupture, because of the pulsative appear- 


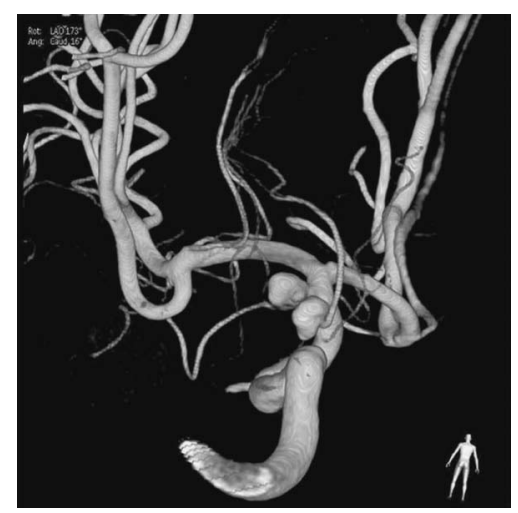

Fig. 1 Rotational three-dimensional digital subtraction angiogram showing adhesion of kissing aneurysms, but the site of branch bifurcation is not clear.

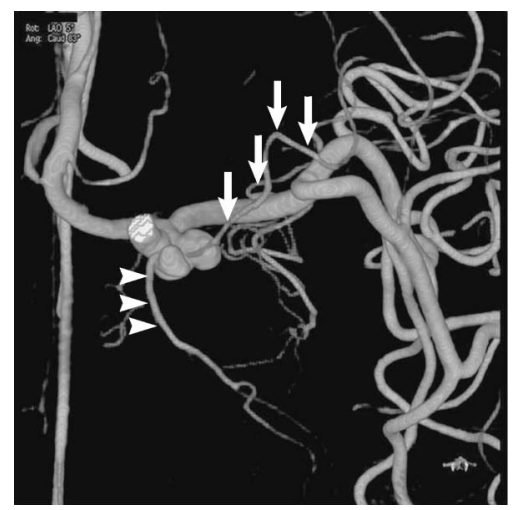

Fig. 2 Rotational three-dimensional digital subtraction angiogram from the inferior direction showing the anterior choroidal artery (AchA) (arrowheads) and duplicated middle cerebral artery (MCA) (arrows) originating from the dome, and the AchA traversing the choroidal point to supply the choroid plexus. This patient does not have an anterior temporal artery, so this territory is expected to be perfused by the duplicated MCA.

ance on streamed two-dimensional digital subtraction angiograms. ${ }^{3)}$ The distal aneurysm was treated first, then the proximal aneurysm (Fig. 3). We employed simple technique for both aneurysms and aimed for intentional partial embolization. An Excelsior ${ }^{\mathrm{TM}}$ SL-10 STR microcatheter (Boston Scientific Corp., Natick, Massachusetts, USA) was used for the distal aneurysm with the tip of the microcatheter shaped by steaming into a 3D curve to fit the form of the carotid syphon. A 3D coil $(3.5 \mathrm{~mm} \times 7.5$ $\mathrm{cm}$ ) was first delivered and packed with 2 ultrasoft coils to avoid deforming the frame of the first coil. An Excelsior ${ }^{\mathrm{TM}}$ SL-10 preshaped $90^{\circ}$ catheter was used for the proximal aneurysm, with a $3 \mathrm{D}$ coil $(3.5 \mathrm{~mm} \times 7.5 \mathrm{~cm})$ first delivered and packed with 2 ultrasoft coils.

The two affected vessels were successfully spared through loose embolization of the aneurysm necks and in areas of bifurcation. The patient was ultimately discharged in satisfactory condition, with no neurological

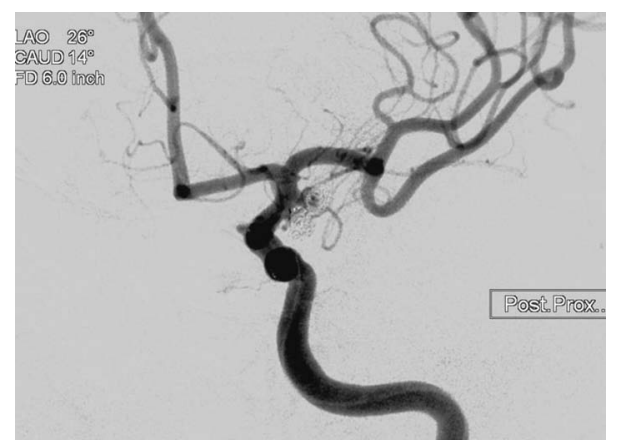

Fig. 3 Digital subtraction angiogram after completion of coil embolization showing both branches spared by loose embolization at the aneurysm necks.

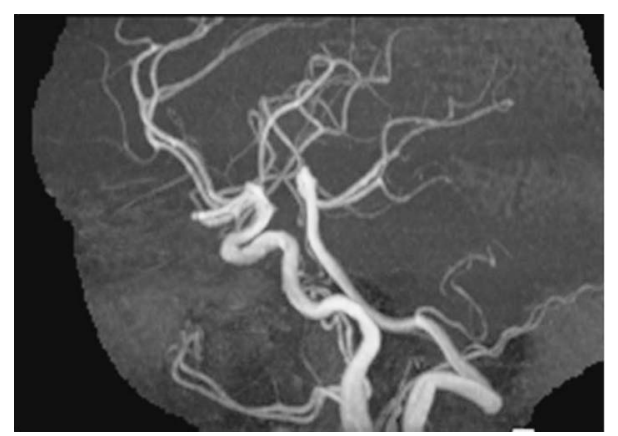

Fig. 4 Time-of-flight magnetic resonance angiogram at 1 year showing no sign of recurrence of the aneurysms.

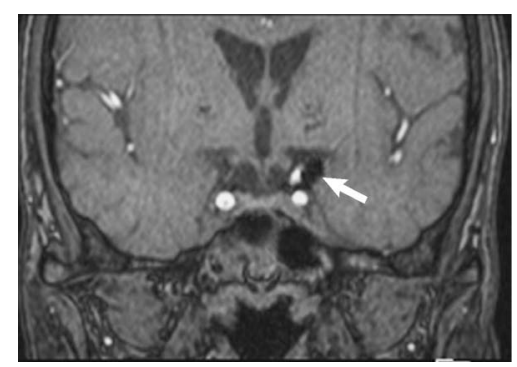

Fig. 5 Time-of-flight magnetic resonance angiogram at 1 year showing no blood flow in the aneurysms (arrow).

deficit. The 6-month and 1-year follow-up time-of-flight magnetic resonance (MR) angiography showed stable occlusion of the aneurysms (Figs. 4 and 5).

\section{Discussion}

The present case of kissing aneurysms originated from the ICA-AchA and an ICA-duplicated MCA, which is highly unusual, although these aneurysms were determined to be kissing aneurysms based only on the angiographical findings, which does not satisfy the strict definition. We could find only 24 published cases of aneurysms developing in 
Table 1 Characteristics of reported duplicated middle cerebral artery aneurysms

\begin{tabular}{|c|c|c|c|c|c|}
\hline Author (Year) & Sex & Side & Treatment & $\mathrm{SAH}$ & Operative complication \\
\hline Stabler $(1970)^{24)}$ & $\mathrm{F}$ & rt & surgery & + & - \\
\hline In et al. $(1981)^{7)}$ & $\mathrm{F}$ & rt & surgery & + & - \\
\hline Fuwa et al. $(1984)^{2)}$ & $\mathrm{F}$ & rt & surgery & + & - \\
\hline Kobayashi et al. (1984) ${ }^{14)}$ & $\mathrm{F}$ & $\mathrm{rt}$ & surgery & + & - \\
\hline \multirow[t]{2}{*}{ Kitami et al. $(1985)^{13)}$} & $\mathrm{F}$ & rt & surgery & + & - \\
\hline & $\mathrm{M}$ & rt & surgery & + & - \\
\hline Takano et al. $(1988)^{27)}$ & M & lt & surgery & - & - \\
\hline Dong et al. $(1991)^{1)}$ & M & lt & surgery & + & - \\
\hline \multirow[t]{2}{*}{ Takahashi et al. (1994) ${ }^{26)}$} & $\mathrm{F}$ & lt & surgery & + & - \\
\hline & M & lt & surgery & + & - \\
\hline Koyama et al. (1995) ${ }^{16)}$ & $\mathrm{M}$ & rt & surgery & + & - \\
\hline Nomura et al. $(2000)^{20)}$ & $\mathrm{F}$ & rt & surgery & + & - \\
\hline Kimura and Furuya $(2000)^{11)}$ & $\mathrm{F}$ & lt & surgery & + & - \\
\hline Tabuse et al. $(2002)^{25)}$ & $\mathrm{F}$ & rt & surgery & + & - \\
\hline Imaizumi et al. $(2002)^{6)}$ & $\mathrm{M}$ & lt & surgery & - & - \\
\hline \multirow[t]{2}{*}{ Hori et al. $(2005)^{4)}$} & $\mathrm{M}$ & rt & surgery & + & - \\
\hline & M & lt & surgery & - & - \\
\hline Kai et al. $(2006)^{9)}$ & $\mathrm{F}$ & lt & surgery & - & - \\
\hline Mizokami et al. (2008) ${ }^{19)}$ & $\mathrm{F}$ & lt & surgery & + & - \\
\hline \multirow[t]{2}{*}{ Miyahara et al. (2009) ${ }^{18)}$} & $\mathrm{F}$ & $\mathrm{rt}$ & surgery & - & - \\
\hline & M & rt & surgery & + & - \\
\hline Kimura and Morita $(2010)^{12)}$ & $\mathrm{F}$ & lt & surgery & - & - \\
\hline Otani et al. $(2010)^{21)}$ & $\mathrm{F}$ & $\mathrm{rt}$ & surgery & + & - \\
\hline Present case & $\mathrm{F}$ & lt & embolization & + & - \\
\hline
\end{tabular}

F: female, M: male, SAH: subarachnoid hemorrhage.

the ICA-duplicated MCAs (Table 1), 1,2,4,6,7,9,11-14,16,18-21,24-27) and none of kissing aneurysms with ICA-duplicated MCA. Duplicated MCA usually supplies the anterior tip of the temporal lobe, or sometimes the area of the AchA, ${ }^{12)}$ so every effort should be made to delineate its path and preserve its integrity.

The treatment of kissing aneurysms is said to be challenging and difficult. We considered both surgical and endovascular treatments to be technically difficult in this case. The close proximity of the aneurysms and the possibility of adhesions at the kissing point indicated problems for intervention with surgical clipping. Basically, the choice of surgical treatment implied the risk of sacrificing the AchA and duplicated MCA, and rupture when freeing the kissing point. The complication of AchA occlusion occurred in 3 of 15 patients after surgical intervention for kissing aneurysms involving the ICA-PCoA and ICA-AchA. ${ }^{10)}$ On the other hand, the precise nature of the blood supply was not totally suitable for the endovascular approach. Tight coil embolization carried the risk of occlusion of both branches. Also, endovascular treatment for kissing aneurysms with coil embolization is rare, and efficacy is uncertain. ${ }^{5,17,22)}$ Only after carefully weighing the safety issues did we finally opt for endovascular treatment. Afterwards, time-of-flight MR angiography was performed on an outpatient basis to periodically monitor the patient's status. Should the aneurysms reconstitute at some future date, additional coil embolization could be needed.

The order of treatment of kissing aneurysms should always be considered. Branches originating near the second aneurysm neck should be sufficiently visible past the first embolized aneurysm and blade of the clip. In this case, we decided to treat the distal aneurysm first. The indications for surgical intervention or coil embolization remain unclear for this rare phenomenon, but establishing the risks and advantages of both treatments are important.

\section{References}

1) Dong LW, Yamada K, Ohta T, Takahashi N: [Ruptured intracranial aneurysm combined with multiple cerebral vessel anomalies; a case report]. No Shinkei Geka 19: 975-978, 1991 (Japanese)

2) Fuwa I, Matsukado Y, Wada H: [Intracranial aneurysms associated with the accessory middle cerebral artery and duplication of the middle cerebral artery. Report of two cases]. Neurol Med Chir (Tokyo) 24: 207-211, 1984 (Japanese)

3) Hayakawa M, Katada K, Anno H, Imizu S, Hayashi J, Irie K, Negoro M, Kato Y, Kanno T, Sano H: CT angiography with electrocardiographically gated reconstruction for visualizing pulsation of intracranial aneurysms: identification of aneurysmal protuberance presumably associated with wall thinning. AJNR Am J Neuroradiol 26: 1366-1369, 2005

4) Hori E, Kurosaki K, Matsumura N, Yamatani K, Kusunose M, Kuwayama N, Endo S: Multiple aneurysms arising from the origin of a duplication of the middle cerebral artery. J Clin Neurosci 12: 812-815, 2005

5) Im SH, Kwon BJ, Jung C, Seo HS, Lee DH, Han MH: Coil embolization of "kissing aneurysms" associated with distal basilar artery fenestration. Clin Neurol Neurosurg 109: 210-213, 2007

6) Imaizumi S, Onuma T, Motohashi O, Kameyama M, Ishii K: Unruptured carotid-duplicated middle cerebral artery 
aneurysm: case report. Surg Neurol 58: 322-324, 2002

7) In S, In K, Kusano N, Mizuki H, Miyagi J, Kuramoto S: [A case of duplication of the middle cerebral artery with ruptured aneurysm on its origin during pregnancy] (author's transl). No Shinkei Geka 9: 337-341, 1981 (Japanese)

8) Jefferson A: The significance for diagnosis and for surgical technique of multiple aneurysms of the same internal carotid artery. Acta Neurochir (Wien) 41: 23-37, 1978

9) Kai Y, Hamada J, Morioka M, Yano S, Kudo M, Kuratsu J: Treatment of unruptured duplicated middle cerebral artery aneurysm: case report. Surg Neurol 65: 190-193, 2006

10) Kanai H, Yamada K, Yamashita N, Masago A, Koide K, Niwa Y: [So-called kissing aneurysms on the same internal carotid artery: report of two cases]. No Shinkei Geka Journal 8: 349-354, 1999 (Japanese)

11) Kimura T, Furuya T: [Three cases with duplication of the middle cerebral artery]. No Socchu No Geka 28: 45-50, 2000 (Japanese)

12) Kimura T, Morita A: Treatment of unruptured aneurysm of duplication of the middle cerebral artery-case report. Neurol Med Chir (Tokyo) 50: 124-126, 2010

13) Kitami K, Kamiyama H, Yasui N: [Angiographic analysis of the middle cerebral artery in cerebral aneurysms-its branching pattern and so-called vascular anomalies]. No Shinkei Geka 13: 283-290, 1985 (Japanese)

14) Kobayashi H, Hayashi T, Otani I, Yoshida Y: [A case of the middle cerebral artery associated with an aneurysm at its origin]. St Marianna Ika Daigaku Zasshi 12: 462-466, 1984 (Japanese)

15) Komiyama M, Yasui T, Tamura K, Nagata $Y, F u$ Y, Yagura $\mathrm{H}$ : "Kissing aneurysms" of the internal carotid artery. Neurol Med Chir (Tokyo) 34: 360-364, 1994

16) Koyama S, Kotani A, Sasaki J, Tazoe M, Tsubokawa T: Ruptured aneurysm at the origin of duplication of the middle cerebral artery-case report. Neurol Ned Chir (Tokyo) 35: 671-673, 1995

17) Matsumoto H, Takechi A, Kohno K, Sasaki U: "Kissing aneurysms" of the anterior communicating artery treated with coil embolization. J Endovasc Ther 12: 750-754, 2005

18) Miyahara K, Fujitsu K, Ichikawa T, Mukaihara S, Okada T, Kaku S: [Unruptured saccular aneurysm at the origin of the duplicated middle cerebral artery: reports of two cases and review of the literature]. No Shinkei Geka 37: 1241-1245, 2009 (Japanese)
19) Mizokami Y, Miyajima Y, Koizumi H, Endo M, Kitahara T, Yamada M, Fujii K: [A case of internal carotid duplication of middle cerebral artery aneurysm]. Currently Practical Neurosurgery 17: 746-751, 2008 (Japanese)

20) Nomura M, Yamashita $T$, Kita D, Kida S, Kajinami K, Yamashita J: Duplication of the middle cerebral artery associated with an unruptured aneurysm. Acta Neurochir (Wien) 142: 221-222, 2000

21) Otani N, Nawashiro H, Tsuzuki N, Osada H, Suzuki T, Shima K, Nakai K: A ruptured internal carotid artery aneurysm located at the origin of the duplicated middle cerebral artery associated with accessory middle cerebral artery and middle cerebral artery aplasia. Surg Neurol Int 1: 51, 2010

22) Saatci I, Cekirge HS, Karcaaltincaba M, Basgun N, Berker M, Timurkaynak E, Ozcan OE: Endovascular treatment of kissing aneurysms at fenestrated basilar artery. Case report with literature review. Surg Neurol 58: 54-58, 2002

23) Sakakibara $Y$, Taguchi $Y$, Ide M, Oshio K, Hiramoto J, Onodera H: [A case of ruptured internal carotid artery "kissing aneurysms": case report and review of the literature]. No Shinkei Geka 34: 297-303, 2006 (Japanese)

24) Stabler J: Two cases of accessory middle cerebral artery, including one with an aneurysm at its origin. Br J Radiol 43: 314-318, 1970

25) Tabuse $M$, Wakamoto $H$, Miyazaki $H$, Ishiyama $N$ : [The usefulness of 3D-CTA for the diagnosis of a ruptured aneurysm at the origin of the duplicated middle cerebral artery: case report]. No Shinkei Geka 30: 327-331, 2002 (Japanese)

26) Takahashi T, Suzuki S, Ohkuma H, Iwabuchi T: Aneurysm at a duplication of the middle cerebral artery. AJNR Am J Neuroradiol 15: 1166-1168, 1994

27) Takano S, Nose T, Oowada T, Shirai S, Maki Y: [Aneurysm arising from duplicated middle cerebral artery. Case report]. Neurol Med Chir (Tokyo) 28: 910-914, 1988 (Japanese)

28) Yasargil MG: Internal carotid artery aneurysms, in Yasargil MG (ed): Microneurosurgery, vol 2. Stuttgart, Georg Thieme Verlag; New York, Thieme-Stratton, 1984, pp 33-123

Address reprint requests to: Michiya Kubo, MD, PhD, Department of Neurosurgery, Saiseikai Toyama Hospital, 33-1 Kusunoki, Toyama 931-8533, Japan. e-mail: michiya@med.u-toyama.ac.jp 